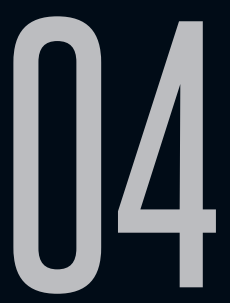

\title{
NÓS SOMOS JOHN MALKOVICH
}

Vinicius Lucas de Souza (UNESP) Aparecido Donizete Rossi (UNESP)

Recebido em $18 \mathrm{fev}$ 2018. Vinicius Lucas de Souza Graduado em Letras Aprovado em 07 jun 2018. (Português/Inglês/Alemão) pela UNESP - Faculdade de Ciências e Letras de Araraquara (2015) e doutorando no Programa de Pós-Graduação em Estudos Literários pela mesma universidade. Desenvolve pesquisa na área de Literaturas Estrangeiras Modernas, com ênfase em Literaturas de Língua Inglesa e Literatura Gótica, focando no motivo do duplo e suas transformações na ficção. Sua produção bibliográfica mais significativa: I. SOUZA, Vinicius Lucas de; ROSSI, Aparecido Donizete. O médico, o monstro e os outros. Abusões, v.3, p.188-229, 2016. II. SOUZA, Vinicius Lucas de; ROSSI, Aparecido Donizete. A emergência do Complexo de William Wilson. Vocábulo, n.IX, p.1-19, 2015; III. SOUZA, Vinicius Lucas de; ROSSI, Aparecido Donizete. A insurgência do Paradoxo JekyllHyde. In: XV Congresso Internacional da ABRALIC: Textualidades Contemporâneas, 2017, Rio de Janeiro. Anais eletrônicos do XV Congresso Internacional da ABRALIC - 07 a 11 de agosto de 2017. Rio de Janeiro: Dialogarts, 2017, v.2, p.1951-1960. Membro do grupo de pesquisas (CNPq) Vertentes do Fantástico na Literatura e do grupo de pesquisas (CNPq) Estudos do Gótico, desde 2014. Recebeu Menção Honrosa no XXVI Congresso de Iniciação Científica da UNESP (1a Fase) concedida pela Comissão Permanente de Pesquisa da UNESP - FCL-Ar pelo trabalho "A revisão 
do Complexo de William Wilson em O médico e o monstro, de Robert Louis Stevenson". Áreas de interesse: Manifestações do Gótico na Ficção; Ficção em Língua Inglesa; Literaturas Estrangeiras Modernas; Literatura Gótica. CV_ Lattes: http://lattes.cnpq. br/5257133057290450. E-mail: viniciuslucassouza@ gmail.com

Aparecido Donizete Rossi é Doutor em Estudos Literários. Possui vínculo institucional com a UNESP - Faculdade de Ciências e Letras de Araraquara, SP. É professor de literatura inglesa. Sua produção bibliográfica mais significativa: I. ZANINI, Claudio; ROSSI, Cido (Orgs.). VERTIGO: Vertentes do Gótico no Cinema. 1.ed. Rio de Janeiro: Bonecker, 2017. II. ROSSI, Aparecido Donizete. The Gothic in Kate Chopin. In: OSTMAN, Heather; O'DONOGHUE, Kate (Orgs.). Kate Chopin in Context: New Approaches. 1.ed. New York: Palgrave Macmillan, 2015, v.1, p.6582. III. ROSSI, Aparecido Donizete; SÁ, Luiz Fernando Ferreira (Orgs.). O Gótico e suas Interseções TeóricoCríticas. 1.ed. Rio de Janeiro: Dialogarts, 2014. Líder do grupo de pesquisas (CNPq) Vertentes do Fantástico na Literatura, desde 2015, e membro pesquisador do grupo de pesquisas (CNPq) Estudos do Gótico, desde 2014. Recebeu Menção Honrosa no XXVI Congresso de Iniciação Científica da UNESP (1a Fase) concedida pela Comissão Permanente de Pesquisa da UNESP - FCL-Ar pela orientação do trabalho de pesquisa de Vinicius Lucas de Souza. Áreas de interesse: Manifestações do Gótico na Ficção; Vertentes do Fantástico na Fiç̧ão; Ficção em Língua Inglesa; Desconstrução; Pós-estruturalismo. CV_ Lattes: http://lattes.cnpq. br/0428069285054155. E-mail: adrossi@fclar.unesp.br

Resumo: O presente artigo objetiva analisar o filme Quero ser John Malkovich (Being John Malkovich, 1999), dirigido por Spike Jonze e escrito por Charlie Kaufman. Focando nas questões sobre a identidade, 
o duplo (Doppelgänger) e a multiplicidade de personalidades e como o jogo identitário distorce o entendimento do eu nos personagens Craig Schwartz e John Malkovich, os quais se entrecruzam por meio de um portal que leva à mente do último, portal este que não só é usado por Schwartz, mas por vários outros, inclusive pelo próprio Malkovich, esfacelando a ilusória ordem do "eu uno" ou a dualidade do "eu e o outro" e mergulhando num abismo legionário de Malkoviches.

Palavras-chave: Quero ser John Malkovich; Identidade; Duplo; Multiplicidade; John Malkovich.

Abstract: This paper aims at analysing the movie Being John Malkovich (1999), directed by Spike Jonze and written by Charlie Kaufman. Focusing on the issues of identity, the double (Doppelgänger), and the multiplicity of personalities and how the identity game twists the understanding of the self in the characters Craig Schwartz and John Malkovich who are interwoven by means of a portal that leads to the latter's mind, which not only is used by Schwartz, but by many others, including Malkovich himself, ripping apart the illusory order of the "unified self" or the duality of "self and the other" and diving into a legionary chasm of Malkoviches.

Keywords: Being John Malkovich; Identity; Double; Multiplicity; John Malkovich.

\section{INTRODUÇÃO}

Ao concentrarmos sobre o campo da identidade humana, geralmente, segundo o senso comum e o que a Ciência entende por "sanidade", a unidade é o estado mental considerado saudável, já que ao apresentar, por exemplo, uma outra personalidade ou ver constantemente alguém igual a si são indícios, de acordo com a 
Medicina, de distúrbios psíquicos, como a esquizofrenia, que gera a confusão contínua entre realidade e alucinações. No entanto, podemos afirmar que somos apenas um, que apresentamos um "eu uno"?

Nos trabalhos de Sigmund Freud, o pai da Psicanálise, isso cai por terra ao relembrarmos de sua estruturação do aparelho psíquico da mente humana: o Ego, a parte organizada da estrutura da personalidade, representando a razão e controlando as necessidades do Id e do Superego; o ld, a parte das pulsões, impulso e instintos, bem como dos traumas reprimidos; e o Superego, a parte que reflete as regras culturais de uma sociedade. Com isso, vê-se difícil a defesa de uma "unidade mental", sólida, congruente, principalmente se levarmos os vários transtornos mentais que emergem na mente, frutos de traumas severos. Se considerarmos o Transtorno Dissociativo de Identidade - caso concordemos com a parcela dos cientistas que alegam a existência desse distúrbio -, sob o qual o indivíduo passa a sofrer momentos de dissociação, ocasionando a emergência de outras personalidades em sua mente, a possibilidade da emergência desse distúrbio contraria a ideia de uma personalidade una, favorecendo a ideia de que talvez a natureza mental dos humanos esteja mais alinhada ao campo da multiplicidade.

No campo da ficção, são frequentes os questionamentos e abordagens que lidam com esses limites identitários, exemplificados nas diversas narrativas que abordam a questão do duplo (Doppelgänger), com seus protagonistas vendendo a sombra ao Diabo (A história maravilhosa de Peter Schlehmih/), perseguidos por alter egos satânicos ("O homem da areia") e com seus olhos 
enublados por reflexos transientes ("William Wilson"), relações entre eus e outros resultando na "[...] equivalência entre o reflexo e a sombra, as duas como imagens iguais opondo-se ao Eu [...]" (RANK, 2013, p.22).

No Cinema, diversos são os filmes que lidam com o tropo do duplo: o famoso caso de Norman Bates e sua mãe em Psicose (1960) ou o caso de Tyler Durden em Clube da luta (1999). Junto aos mencionados, jogando com essas fronteiras de identidades e alteridades, está o filme Quero ser John Malkovich (1999), dirigido por Spike Jonze com roteiro de Charlie Kaufman, em que um portal que leva à mente do ator John Malkovich, interpretado por ele mesmo, é encontrado por um titereiro, Craig Schwartz, interpretado por John Cusack, e, posteriormente, comercializado, permitindo à clientela experimentar a sensação de duplicidade, de ser outra pessoa. No entanto, como Schwartz descobrirá, "ser John Malkovich" significa não somente observar suas ações, como também controlá-las, podendo modelar e remodelar sua própria personalidade e a de Malkovich.

Nas linhas a seguir, portanto, pretendemos abordar as questões de identidade, duplo e múltiplas personalidades no filme em questão, focando nos jogos que distorcem os limites entre as personagens, especialmente Schwartz e Malkovich, nas barreiras que separam títere de seu titereiro, pulverizando a unidade e a dualidade do eu numa legião de outros, num abismo de eus, outros e muitos Malkoviches.

\section{QUEM É JOHN MALKOVICH?}

Um homem que vive seu cotidiano toma consciência de sua natureza frente a um espelho: um títere manipulado pelas linhas 
de um deus, um deus humano cuja aparência é igual à sua, assim se revoltando, quebrando tudo à sua volta, inclusive a citada superfície especular e, por fim, terminando sua dança de desespero e desilusão na frustração de estar aprisionado em sua própria identidade, preso em si mesmo, preso numa cópia manipulada, à sombra e à mercê das linhas do Destino que o fazem questionar se o que vive é real e, pior, se ele mesmo é real. Saber quem é o real e quem a duplicata é uma das dúvidas que sempre pairam na ficção sobre o duplo, questionamento que vemos no filme Quero ser John Malkovich e que Clément Rosset expõe ao discorrer sobre o Doppelgänger:

É verdade que o duplo é sempre intuitivamente compreendido como tendo uma realidade "melhor" do que o próprio sujeito - e ele pode aparecer neste sentido como representando uma espécie de instância imortal em relação à mortalidade do sujeito. Mas o que angustia o sujeito, muito mais do que a sua morte próxima, é antes de tudo a sua nãorealidade, a sua não-existência. Morrer seria um mal menor se pudéssemos ter como certo que ao menos se viveu; ora, é desta vida mesma, por mais perecível que por outro lado possa ser, que o sujeito acaba por duvidar no desdobramento de personalidade. No par maléfico que une o eu a um outro fantasmático, o real não está do lado do eu, mas sim do lado do fantasma: não é o outro que me duplica, sou eu que sou o duplo do outro. Para ele o real, para mim a sombra. (2008, p.88-89 - grifo do autor)

No plano real ou nos domínios das sombras é a dúvida, a hesitação que insurge ao tentar definir quem é o original e quem o sósia, quem é o verdadeiro e quem a falsificação. Dificilmente esse dilema é resolvido, levando a nos interrogar se "realmente" 
haveria uma diferença entre um e outro, em outras palavras, se o "original" existe. Para Rosset, resta ao eu a sombra, a máscara. No filme, muitos personagens mascaram-se, vestem o rosto de John Malkovich sobre os seus próprios. Exacerbando a visão do filósofo francês - exacerbação que discutiremos ao longo do artigo -, talvez não se trate de um jogo dialético entre o real e o irreal, mas de uma mascarada, em que os rostos que dançam são somente outras máscaras, outros duplos de duplos.

Assim começa a narrativa cinematográfica de Quero ser John Malkovich, com a "Dança de Desespero e Desilusão de Craig", intitulada por seu criador, o titereiro Craig Schwartz, constantemente frustrado por sua invisibilidade artística, por um público que não nota seu talento e seus questionamentos na arte dos títeres. A dança apresentada em sua oficina guia e prevê os eventos futuros que enovelarão Craig, sua esposa, Lotte, interpretada por Cameron Diaz, e John Malkovich.

Figura 1. O títere e o espelho. ${ }^{1}$

1 Fonte: Cena do filme Quero ser John Malkovich. 
À procura de um emprego, Schwartz é contratado como arquivista na Lestercorp, empresa localizada no andar "sete e meio" do edifício Mertin-Flemmer, em Nova lorque. Ao conhecer o seu futuro chefe, o Dr. Lester, e sua secretária, o protagonista percebe certa estranheza, como o fato de que o doutor acredita que as pessoas não conseguem entender sua fala ou ainda a secretária que entende tudo errado. Mais do que se destacar por sua bizarra aura, o andar sete e meio - assim como a plataforma nove e três quartos na saga Harry Potter; a estrutura bidimensional nos romances $O$ talismã (1984), Coraline (2002) e Stardust (1999); o laboratório do Departamento de Energia dos Estados Unidos da cidade de Hawkins que guarda o portal entre dois universos opostos da série de web televisão Stranger Things - indicia uma certa fronteira, uma zona limítrofe entre duas realidades, mesclando elementos e seres desses dois universos, o que logo é fortemente sustentado pela descoberta do protagonista de uma pequena porta que leva a um túnel lamacento e, por fim, à mente do ator norte-americano John Malkovich.

Dessa maneira, esse portal difere-se do padrão de obras de fantasia, isto é, o portal entre dois mundos, permitindo a comunicação e a passagem de seres de um para o outro. No exemplo que citamos, no universo criado por J. K. Rowling, uma das maneiras dos bruxos movimentarem-se entre o mundo mágico e o não mágico, o chamado "trouxa", é por meio da plataforma nove e três quartos, localizada na estação de trem King's Cross, em Londres. No entanto, o portal do filme não se mantém numa relação mundo físico-mundo físico, mas entre o universo físico do enredo fílmico e a mente de Malkovich, permitindo ao viajante 
entre planos, a princípio, sentir tudo o que o ator sente e, após um curto momento, cair na autoestrada de Nova Jersey. Em outras palavras, ele permite tornar-se outra pessoa, transformar-se no duplo de John. Interessante perceber que essa visão interna da vida do ator é disponibilizada ao espectador pelo quadro composto na câmera, possibilitando que não só os personagens tenham a chance de experimentar ser Malkovich, como também o próprio público. Com isso, a própria estrutura fílmica plasma essa duplicidade, convergindo tema e forma ao duplo.

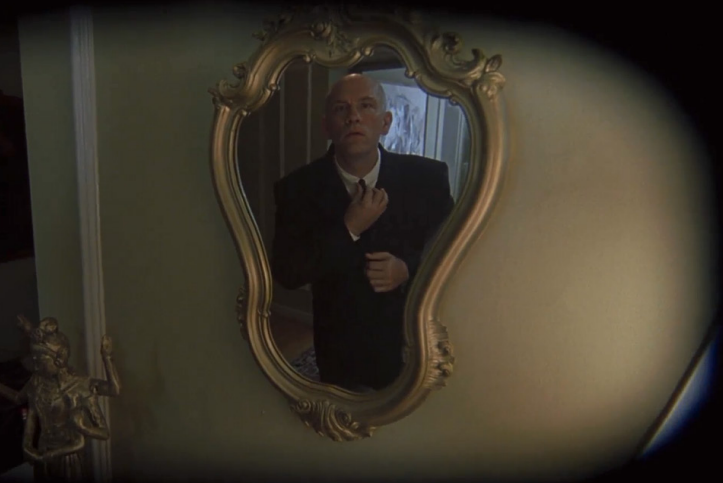

Figura 2. Eu sou John Malkovich. ${ }^{2}$

Schwartz, nesse primeiro momento, torna-se o acompanhante oculto do ator em suas andanças, escondido nas sombras de sua consciência, compartilhando suas sensações. Apesar de um detalhe extra fílmico e uma semelhança que mais parece uma coincidência, o primeiro nome, que tanto Cusack quanto Malkovich compartilham, "John", aumenta a carga dúplice que assombra esses personagens, uma vez que seus respectivos atores, os "médiuns" que encarnam 
esses papéis, passam a nutrir certa semelhança também. Durante nossa análise, muitos pontos extra fílmicos acabarão emergindo, como o exposto aqui - a duplicidade entre Schwartz e Malkovich e seus respectivos atores, Cusack e Malkovich - , assim como referências a outros filmes de Kaufman e Jonze, o que eventualmente enfraquecerá a leitura de que tais semelhanças sejam gratuitas.

É mister notar que no interior da mente o corpo do titereiro não se manifesta em termos materiais, o que enubla a natureza de Schwartz enquanto parceiro íntimo de Malkovich. Numa possível leitura, ele se manifestaria numa forma diferente de configuração corporal, capaz de ser evocada pela passagem pelo túnel lamacento, o que implicaria no portal exceder sua função de comunicação entre o plano físico e o plano mental "malkovichiano", exercendo também o papel de uma espécie de filtro corpóreo, transformando a configuração física de seus usuários enquanto duplos do ator, além de possibilitar a coexistência de duas mentes num corpo.

Com isso, o túnel passa a adquirir uma função similar à da droga do Dr. Henry Jekyll em O médico e o monstro (1886), de Robert Louis Stevenson: ao tomar o seu fármaco, Jekyll transforma-se em Edward Hyde, alguém repulsivo pela mera aparência, mudando sua prévia moradia carnal numa barca de duas personalidades e muitas outras mais $^{3}$, capaz de emanar essa replicação de fragmentos identitários à própria estrutura narrativa do romance. Coincidentemente, três anos antes de atuar no filme dirigido por Jonze, John Malkovich atuara em $O$ segredo de Mary Reilly (1996), baseado no romance Mary Reilly (1990), cujos enredos focam na empregada Mary

3 Essa perspectiva do romance $O$ médico e o monstro é por nós abordada no artigo "O médico, o monstro e os outros", presente no volume 3 da revista Abusões. Vide referências. 
Reilly, interpretada por Julia Roberts, e sua perspectiva, bem como interferência, sobre o que se passa na casa do respeitável Dr. Henry Jekyll e sua relação com seu assistente, Edward Hyde, ambos interpretados por Malkovich.

O túnel de lama, assim, concede a possibilidade de ser outro, remodela o barro definitivo, para usarmos o mito bíblico a uma outra configuração, uma nova forma, um renascimento. A partir dessa perspectiva, o túnel cumpre as vezes de um útero, um ventre inumano que leva quem nele entrar a essa outra vida, a John Malkovich. Como descreve a esposa de Schwartz, esse mecanismo interdimensional confere a John um lado feminino, como se fosse a "vagina" de John Malkovich, duplicando mais uma vez o ator, agora acrescentada uma esfera feminina à sua masculinidade, como que atribuindo-Ihe dois tipos de genitália, a masculina e a feminina, e o tornando uma espécie de hermafrodita, cuja "vagina" excede suas funções tradicionais, permitindo a entrada de um ser humano completo na corporeidade de Malkovich. Considerando isso, mais do que uma experiência de ser outro, os usuários do túnel transam com o ator, que ao longo do filme, apontará não a uma única relação sexual e sim a bacanais, em que mais de uma pessoa "penetra" o túnel, bem como várias ao mesmo tempo. Logo, a experiência legionária que ocorre no corpo de Malkovich não só transgride a esfera da identidade, como também desalinha a ordem sexual, convergindo a questão da alteridade a uma experiência orgiástica; transformar-se noutra pessoa contempla, nesse caso, conhecê-la sexualmente.

Dimanante disso, o portal de Malkovich plasma-se como um anexo de seu corpo, um órgão extracorporal que possibilita 
um contato completo entre dois seres, em níveis de corpo e alma, uma espécie de prótese. Malkovich, então, excede o padrão humano ao contar com essa prótese ou órgão adicional, direcionando-se a algo que distoa do padrão humano, em outras palavras, configurando-se como um mutante: um ser que, devido a operações celulares aleatórias em seu corpo, diferenciou-se da humanidade, apresentando características a mais ou a menos do que o ser humano comum. Para Jean Baudrillard, John Malkovich é, portanto, uma criança-prótese, "[...] embrião de todas as formas sonhadas de mutação [...]" (2004, p.29), igualando-se, por conseguinte, aos ícones expostos pelo teórico francês, Michael Jackson, Cicciolina, Madonna, Andy Warhol, "São todos mutantes, travestis, seres geneticamente barrocos, cujo visual erótico esconde a indeterminação genética. Todos são gender-benders, trânsfugas do sexo" (2004, p.28). Dobrando as questões de gênero, sexo e identidade, Malkovich, como seu portal, desvela-se uma figura fronteiriça e maleável, aberto às possibilidades do "entre", entreidentidades, entre-gêneros, entre-eus, entre-outros.

Nessa subversão do corpo e da identidade, outros aspectos da mente do ator não permanecem intocados, ao relembrar que o corredor entre dimensões reflete seus passageiros na personalidade do ator, um espelhamento que joga um corpo humano na mente de um indivíduo, cujos limites de sua psique desestabilizam-se em função da vinda desse(s) outro(s). Levando em consideração essa desestabilização - que contempla a sobreposição de personalidades, anestesiando a personalidade John Malkovich - , nota-se que mergulhar no ator num nível tão profundo, até os recantos do subconsciente - como acontece 
em dado momento com duas personagens - , usar a máscara do protagonista é vestir temporariamente esse rosto, fazer o eu tornar-se outro. Considerada essa transformação temporária, esse contato íntimo entre alteridades não descartaria possíveis trocas ou contaminações de uma mente a outra, disseminações de traumas reprimidos ou replicações de memórias. Com o corredor funcionando similarmente ao espelho, segundo Umberto Eco, isto é, "[...] uma prótese absolutamente neutra, e permite que se obtenha o estímulo visual onde o olho não poderia alcançar [...]. Como prótese, os espelhos são canais. Um canal é cada medium material que permite a passagem de informação [...]" (1989, p.18 grifo do autor), é de se supor que haja uma comunicação entre as identidades pelo portal lamacento, o que implica na influência de um sobre o outro e vice-versa. Nesse sentido, entrar em Malkovich significa ir além de observar sua vida, significa espelhar traços de sua consciência e seu inconsciente e ser contaminados por eles. Não podemos considerar, assim, que o preço de vivenciar o ator seja gratuito, muito menos descartar a possibilidade de, após o "passeio no ator", levar souvenirs consigo, replicar na própria mente traços da psique de John Malkovich.

Nesse complexo jogo transgressivo do corpo, da identidade e da mente, somado à organicidade do lamaçal, o túnel mascarante atua como o phármakon na visão de Jacques Derrida:

A magia da escritura [...] é, pois, aquela de um disfarce que dissimula a morte sob a aparência do vivo. O phármakon apresenta e abriga a morte. Ele dá boa figura ao cadáver, o mascara e disfarça. Perfuma-o com sua essência [...]. O phármakon designa também o perfume. Perfume sem essência, 
[...] droga sem substância. Ele transforma a ordem em enfeite, o cosmos em cosmético. A morte, a máscara, o disfarce, é a festa que subverte a ordem da cidade, tal como ela deveria ser regulada pelo dialético e pela ciência do ser.

[...] O esperma, a água, a tinta, a pintura, o tingimento perfumado: o phármakon penetra sempre como o líquido, ele se bebe, se absorve, se introduz no interior que ele marca, primeiramente, com a dureza do tipo, invadindo-o em seguida e inundando-o com seu remédio, sua beberagem, sua bebida, sua poção, seu veneno.

No líquido, os opostos passam mais facilmente um no outro. O líquido é o elemento do phármakon. E a água, pureza do líquido, se deixa o mais facilmente, - mais perigosamente, penetrar e depois se corromper pelo phármakon, com o qual se mistura e se compõe tão rapidamente. $(2005$, p.92;102)

Ao encontrar o portal, muitas mudanças passam a operar na vida de Craig Schwartz e daqueles que o circundam: a primeira é em relação a Lotte, sua esposa, que logo na primeira vez que experimenta ser Malkovich, descobre-se transexual, isto é, identifica a disforia entre sua identidade de gênero e seu sexo. Estupefata com as novas sensações, o corpo do ator fazIhe sentido à personalidade, agrada-Ihe. Em outras palavras, o túnel lamacento possibilita-lhe a adequação entre identidade de gênero e sexo, funcionando, assim, similarmente a uma cirurgia de redesignação sexual.

Além disso, o portal também impacta a vida de uma colega de trabalho de Schwartz, Maxine Lund, interpretada por Catherine Keener, que sugere a criação da empresa J.M. Inc. e, 
consequentemente, lucrar sobre a "experiência Malkovich". Várias pessoas compram o serviço oferecido e o empreendimento é agraciado pelo enorme sucesso. A duplicidade entre o titereiro e o ator, por conseguinte, é exponenciada severamente, já que não mais um e outro, mas outros e outros dividem o cotidiano com John Malkovich. Ser Malkovich é algo que o dinheiro fornece agora: ver com olhos estrangeiros vira uma mercadoria, viver outra vida agora é uma questão financeira; comprar passa a englobar o comprar-se.

Ao longo da experimentação corporal no ator, Lotte e Maxine apaixonam-se, enquanto aquela usa a máscara de Malkovich. Schwartz, movido por uma paixão por Lund, transa com ela enquanto no corpo de seu outro, conseguindo, com muito esforço, mover o braço de Malkovich e até falar uma pequena frase. Com isso, a observação mental passa a um estatuto de incorporação: como numa possessão divina ou demoníaca, Craig Schwartz começa a controlar os movimentos e fala de seu hospedeiro; de acompanhante a obsessor, Schwartz comprova seu dom na arte de titerear, controlando Malkovich. Vale lembrar que além de ser um titereiro, ele também constrói seus títeres: em sua coleção constam o boneco na primeira cena do filme que é uma cópia de sua aparência, bem como as cópias de Maxine e Lotte, mantidas em sua oficina. Não somente um controlador de bonecos, o titereiro também manifesta-se como um criador: Schwartz dá um passo além de Victor Frankenstein, do romance Frankenstein (1818), de Mary Shelley, não só desenvolvendo suas criaturas, como também controlando-as. Criar, copiar e controlar fazem-no, por conseguinte, o mestre titereiro. 


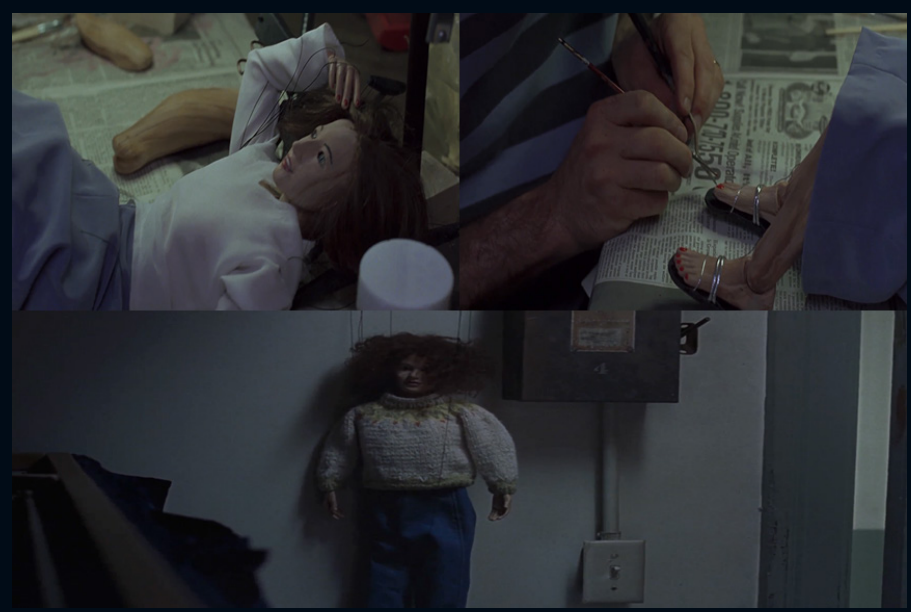

Figura 3. Criando e controlando títeres. ${ }^{4}$

Apesar de pontual, esse período de controle de Craig assusta John, fazendo com que ele recorra a um amigo, Charlie Sheen, que também se interpreta. Malkovich e Sheen são os únicos que interpretam a si mesmos no filme, duplicando-se na narrativa cinematográfica ao representar versões de si mesmos, com pequenos detalhes diferentes, por exemplo, o nome inteiro de Malkovich no filme é "John Horatio Malkovich", quando seu nome em nossa realidade é "John Gavin Malkovich". Consequentemente, insta-nos a questão: no caso de Quero ser John Malkovich, atuar é ser a si mesmo? Podemos ver certa semelhança entre "ser alguém" e "atuar alguém", algo suportado no filme, uma vez considerado o comentário repetido várias vezes que Malkovich seria um ladrão de joias num filme. A princípio, respondendo a um taxista, ele diz que não interpretou nenhum ladrão de joias, mas a provocação permanece ao ser repetida por outras personagens, instando-nos se esse ator não teria sido confundido com John Malkovich ou ainda 
alguém passando-se por ele, um duplo que imita John Malkovich. Como se vê, a teia que se forma ao redor do personagem em questão dobra-se e se desdobra a cada costura.

\section{MALKOVICH, NÓS SOMOS MALKOVICHES}

Suspeitando que Maxine, com quem desenvolvera uma relação, tenha algo a ver sobre o que lhe acometera, Malkovich segue-a até $o$ prédio Mertin-Flemmer e lá encontra a J.M. Inc. e uma fila de clientes que o esclarecem sobre o que ali é ofertado: ser John Malkovich. Irado com Schwartz e Lund, ele decide entrar em seu próprio portal e, a partir disso, ele "vê-se": Malkovich surge num restaurante em que todas as outras pessoas, adultos e crianças, homens e mulheres, possuem o rosto e a voz iguais aos seus, variando somente suas configurações corporais abaixo da cabeça; tudo escrito é o nome "Malkovich" e ao falarem somente pronunciam "Malkovich". Um universo em que só há John Malkoviches e uma única palavra, "Malkovich"; uma dimensão infernal, em que a repetição de si no espaço e no discurso é contínua e perpétua. Como nos ensina Sartre, "O inferno... são os Outros" (1977, p.98), outros dos quais não se consegue escapar, outros que nos infernizam, outros que são nós mesmos.
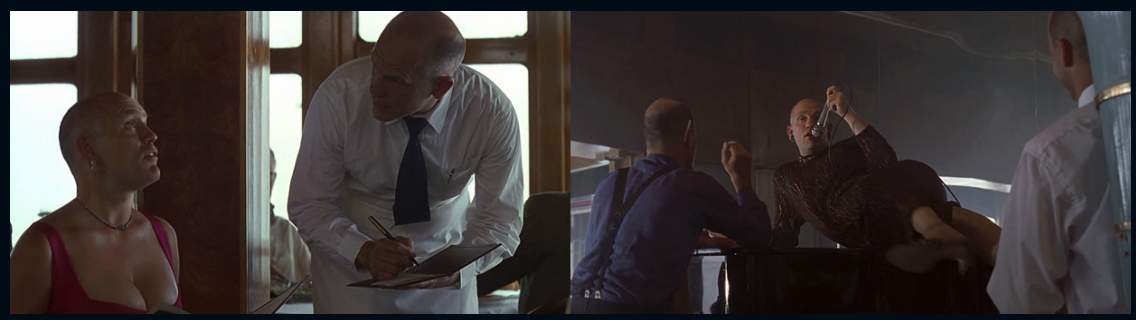

Figura 4. Malkovich. ${ }^{5}$

5 Fonte: Cenas do filme Quero ser John Malkovich. 
Além disso, enquanto ele experimenta essa super dose explosiva de si, há um cliente em sua mente, que o observa observando-se. Um mise-en-abîme mental, uma mente no interior de uma mente, que, por sua vez, adentra em si mesma, enovelandose num labirinto identitário, numa de rede de personalidades em que a própria significação do eu começa a esmorecer, começa a se tornar estranha, unheimliche, de acordo com Freud: "[...] aquela categoria do assustador que remete ao que é conhecido, de velho, e há muito familiar" (1996, p.238). Ao entrar em seu próprio portal, em sua própria mente, os "eus" de Malkovich, apesar de familiares, estranham-lhe, apavoram-lhe, isto é, o ator aterroriza-se frente ao "[...] reprimido que retorna" (FREUD, 1996, p.258 - grifo do autor).

Note-se que esse excessivo mise-en-abîme mental será retomado em A origem (2010), dirigido e escrito por Christopher Nolan, no qual, por meio de uma máquina, é possível criar labirintos de sonhos dentro de sonhos, podendo-se controlar suas configurações, bem como introduzir ideias na mente de uma pessoa. Como Quero ser John Malkovich, A origem exacerba as possibilidades de atuação na mente humana, jogando com os limites entre sonho e realidade, bem como com uma eventual queda num limbo subconsciente, o que ocorre no fim dos filmes de Jonze e Nolan.

Voltando a entrar em Malkovich, Craig Schwartz descobre como manter-se em poder da mente do ator, dominando seu novo títere além do breve período que os iniciantes dispõem e exibindo seu poder máximo como o mestre titereiro ao executar sua "Dança de desespero e desilusão de Craig" a Maxine, que se entregara à novidade de Schwartz e a seu amor. John Malkovich torna-se o 
boneco de Craig e este, por meio de seu medium, duplica a dança nesse seu novo corpo e criatura.

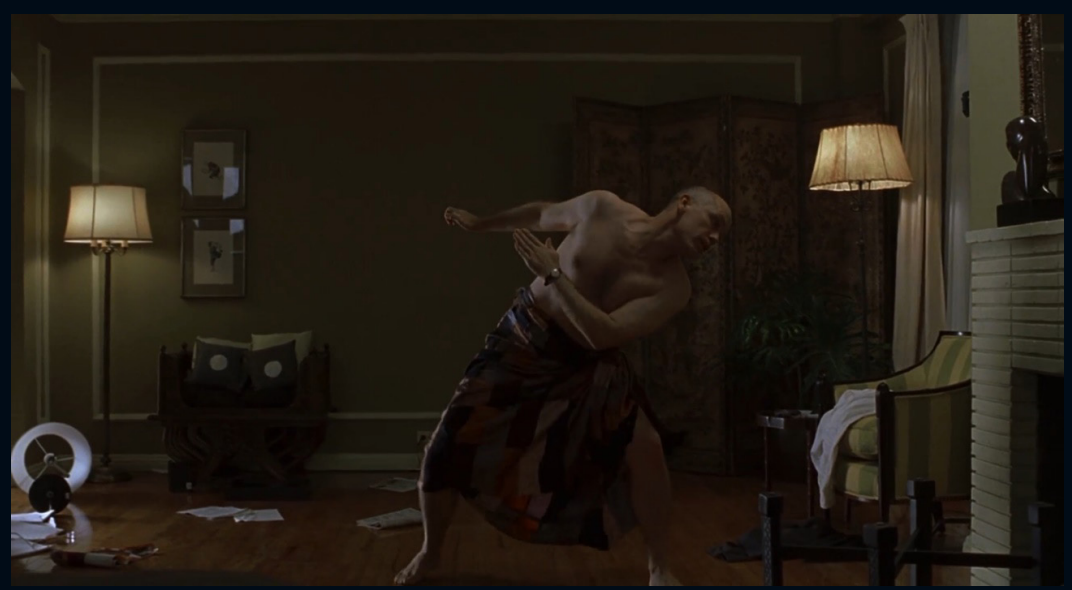

Figura 5. A dança de desespero e desilusão de Craig. ${ }^{6}$

Nesse espelhamento da primeira cena do filme, em que Craig controla o boneco "à sua imagem e semelhança", agora a imagem da criatura difere-se da de seu controlador/criador, no entanto, a imagem do criador também se altera, passando a possuir, usurpar a de sua criatura. O criador transforma-se em criatura, sem abandonar seu estatuto divino: ele adota uma nova roupa, como o próprio Schwartz-Malkovich (Schwartz em Malkovich) afirma um terno que ele passara a gostar de usar, sendo este seu segredo para conseguir controlar o corpo continuamente, não encará-lo como seu inimigo, mas fazendo amizade com essa casca - uma vestimenta de carne e osso, similarmente ao que o assassino Buffalo Bill realiza com os cadáveres de suas vítimas, privando-os de suas peles e, a partir delas, costurando sua própria roupa feminina em $O$ silêncio dos inocentes (1991).

6 Fonte: Cena do filme Quero ser John Malkovich. 
Além dessa passagem, em que temos o processo de duplicação na própria estrutura fílmica, uma outra cena converge a temática abordada à forma: ao tentar escapar de suas amarras - feitas pelo titereiro - dentro da jaula de seu pet, Elijah, o chimpanzé, Lotte é auxiliada pelo animal, que toma essa atitude após lembrar de sua captura, que se dera ao tentar remover as amarras de seus pais. O trecho da memória do animal é plasmado ao espectador com legendas, "traduzindo" a linguagem empregada pela família símia, além da câmera assumir a visão do chimpanzé, promovendo o mesmo processo que o túnel lamacento apresenta a seus usuários. Com isso, não só sua temática, mas também a estrutura do filme está impregnada com a questão do assumir outros olhos, assumir outra personalidade, seja nas cenas em que Craig e Lotte experimentam o olhar de Malkovich ou na captura de Elijah.

\section{Son, untie your father and me!}

Figura 6. A visão e captura de Elijah. ${ }^{7}$

Fora de seu cativeiro, Lotte segue à mansão do Dr. Lester, a qual visitara anteriormente junto com o marido para um jantar, lá 
descobrindo uma sala dedicada inteiramente a John Malkovich, com uma linha do tempo de sua vida e conquistas. Conversando com o velho a respeito de uma obsessão sua por Malkovich e na sua ânsia por querer sê-lo, Lester acaba revelando que, na verdade, ele não é o Dr. Lester, mas o Capitão Mertin. Noventa anos atrás, ele descobrira um portal que o levava a um corpo, possibilitando que sobrevivesse ao tempo, pulando de corpo em corpo e, agora, prestes a pular à sua nova casca, John Malkovich. Contudo, se ele não entrar até a meia-noite do quadragésimo quarto aniversário do ator, momento em que o corpo matura, o usuário do túnel é desviado à próxima casca, em seu estágio larval, isto é, a um recémnascido, sendo absorvido por ele e ficando preso em sua mente, condenado a assistir a vida desse ser inapto a controlá-lo.

Logo, o mecanismo do túnel é utilizado por Mertin como uma forma de trapacear a morte, uma maneira de atingir a imortalidade - um caminho muito parecido ao que ocorre no conto "A história do falecido Sr. Elvesham" (1896), de H. G. Wells, no qual a troca de corpos dá-se por meio da ingestão de uma bebida -; ser imortal, assim, desvela-se uma questão de adaptar-se a outros eus, uma mudança constante de eus em outros, de outros em eus, corroborando a perspectiva de Otto Rank, segundo a qual a imortalidade e o duplo caminham sempre juntos:

o narcisismo primitivo, sentindo-se ameaçado pela inevitável anulação do Eu, criou como primeira representação da alma uma imagem o mais idêntica possível ao Eu corpóreo, portanto, um verdadeiro duplo. Assim, a ideia da morte é desmentida através de uma duplicação do Eu que se corporifica na sombra ou no reflexo. (2013, p.138) 
Depois de oito meses, Schwartz-Malkovich não finge ser John Malkovich, seguindo a mesma rotina que o ator conduzia anterior às interferências em sua vida, mas altera a personalidade pública dele ao perseguir o seu sonho de ganhar notoriedade com a arte de titerear e trazendo uma marca de Craig Schwartz ao títere carnal: o cabelo comprido.

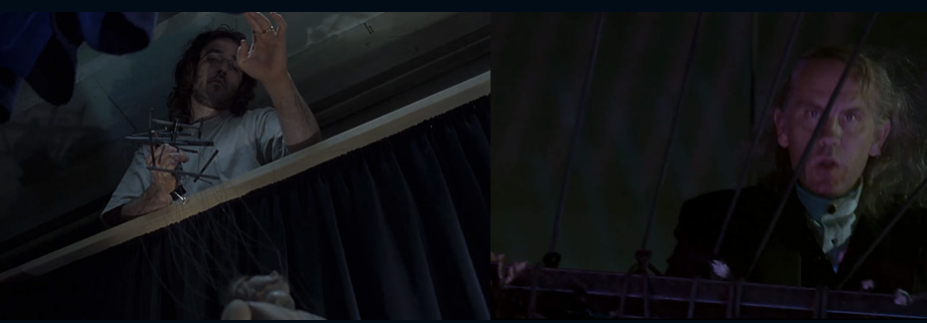

Figura 7. Craig, o titereiro e o novo John Malkovich. ${ }^{8}$

Uma vez tendo desistido da carreira de ator, Schwartz-Malkovich ganha fama mundial, sendo reconhecido como um mestre titereiro. Acompanhamos essa notoriedade crescente por meio de um documentário televisionado - o metafílmico, um documentário inserido na estrutura do filme - , que transmite várias cenas das apresentações do artista. Numa delas, ele controla um títere que, por sua vez, controla um títere menor, não só metaficcionalizando sua própria condição existencial, mas apresentando o mesmo miseen-abîme identitário que Malkovich testemunhou ao entrar em seu próprio universo; em outras palavras, a perda da ideia de original e a vinda do simulacro, conforme entendido por Baudrillard: "[...] efeito de imaginário escondendo que não há mais realidade além como aquém dos limites do perímetro artificial" (1991, p.23). Simulacros de simulacros de simulacros, ou nas palavras de Derrida, 
O Mímico está atuando a partir do momento em que ele é dominado por nenhuma ação real e mira em direção de nenhuma forma de verossimilhança. $O$ ato sempre desempenha uma diferença sem referência, ou invés disso sem um referente, sem nenhuma exterioridade absoluta, e, portanto, sem nenhum interior. O Mímico mimica a referência. Ele não é um imitador; ele mimica a imitação. O hímen interpõe-se entre a mímica e a mimēsis ou invés disso entre a mimēsis e a mimēsis. Uma cópia de uma cópia, um simulacro que simula o simulacro platônico - a cópia platônica de uma cópia bem como a cortina hegeliana perderam aqui a isca do referente presente e, então, encontram-se perdidas para a dialética e a ontologia, perdidas para o conhecimento absoluto. 0 que é também, como Bataille literalmente o teria, "mimicado." Nessa alusão perpétua sendo performada no fundo de trás do entre que não tem fundo, nunca se pode saber a que a alusão alude, a não ser que seja a si mesma no processo de aludir, tecendo seu hímen e manufaturando seu texto. Donde a alusão torna-se um jogo, conformando-se apenas às suas próprias regras formais. Como seu nome indica, a alusão joga. (1981, p.219 - grifo do autor) ${ }^{9}$

$9 \mathrm{Na}$ tradução consultada: "The Mime is acting from the moment he is ruled by no actual action and aims toward no form of verisimilitude. The act always plays out a difference without reference, or rather without a referent, without any absolute exteriority, and hence, without any inside. The Mime mimes reference. He is not an imitator; he mimes imitation. The hymen interposes itself between mimicry and mimēsis or rather between mimēsis and mimēsis. A copy of a copy, a simulacrum that simulates the Platonic simulacrum the Platonic copy of a copy as well as the Hegelian curtain have lost here the lure of the present referent and thus find themselves lost for dialectics and ontology, lost for absolute knowledge. Which is also, as Bataille would literally have it, "mimed." In this perpetual allusion being performed in the background of the entre that has no ground, one can never know what the allusion alludes to, unless it is to itself in the process of alluding, weaving its hymen and manufacturing its text. Wherein allusion becomes a game conforming only to its own formal rules. As its name indicates, allusion plays". Os trechos dos textos em inglês aqui citados foram traduzidos pelos autores do presente artigo. 


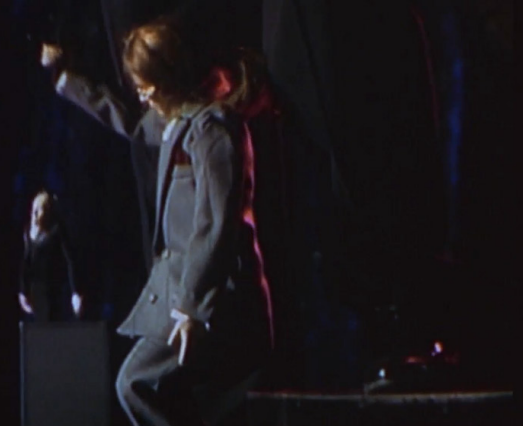

Figura 8. Títere do títere do títere. ${ }^{10}$

Preso na chantagem do Dr. Lester com o fim de expelir Schwartz do corpo de Malkovich, Schwartz-Malkovich não consegue decidir entre voltar a viver como Craig Schwartz e salvar a vida de Maxine. Enquanto no dilema, Lotte e Maxine brigam e entram no portal lamacento enquanto uma foge da outra. Ao fazer isso, elas caem na mente de Malkovich, mas dessa vez em seu subconsciente, presenciando, durante a perseguição e fuga, as memórias, frustrações e experiências de John - é interessante que em uma delas, vemos um garoto observando, ao que tudo indica, os pais transando, o que fortemente rememora o caso do "Homem dos Lobos" que Freud relata em seu ensaio "História de uma neurose infantil" (1918), que, segundo o relato de Freud sobre as sessões psicanalíticas empreendidas, ver os pais transando fora uma das experiências traumáticas infantis do paciente -, mais uma vez causando a permanência de mais de uma pessoa na mente de Malkovich, que pulula como uma multidão. A mente do ator assemelha-se, assim, ao protagonista do conto "O 
homem da multidão" (1840), de Edgar Allan Poe, que acompanha obsessivamente as multidões e massas que circulam pelas ruas de Londres, nunca permanecendo só.

Estas cenas pelas memórias de Malkovich ecoarão mais tarde em Brilho eterno de uma mente sem lembranças (2004), cujo roteiro também é de autoria de Charlie Kaufman, no qual o protagonista decide ter suas memórias apagadas por uma máquina capaz de realizar tal feito. No entanto, ele se arrepende e tenta escapar, mentalmente, desse apagamento, junto com a memória de sua namorada, percorrendo vários momentos de sua vida. A duplicação e replicação tematizadas no filme de Jonze tomam um aspecto extrafílmico, atuando fora de Quero ser John Malkovich e o ecoando em outras obras, como um vírus, contaminando tudo e todos e se disseminando pela ficção.

Com as duas fora de John Malkovich, Lotte e Maxine reconciliam-se por meio de um segredo da última sobre sua gravidez: ela engravidara a partir da relação com Malkovich quando a esposa de Schwartz estava no interior do ator. $\mathrm{E}$ Schwartz acaba também saindo de Malkovich, cedendo à chantagem de Lester, mas ao cair na autoestrada, não só seu corpo é expelido, como também o pedaço de madeira que levara consigo na primeira vez que entrara em John Malkovich: tanto o mestre titereiro como sua ferramenta são expelidos nessa desistência voluntária do corpo do ator, que marcara não somente sua queda, mas também seu controle sobre o corpo do ator. A desistência de Craig, então, assume uma espécie de morte de sua segunda vida, da vida que criara enquanto Malkovich, da vida que moldara e vivenciara. Apesar do extremo vínculo com 
sua criatura, Schwartz abandona-a, seguindo eventualmente os passos de Frankenstein.

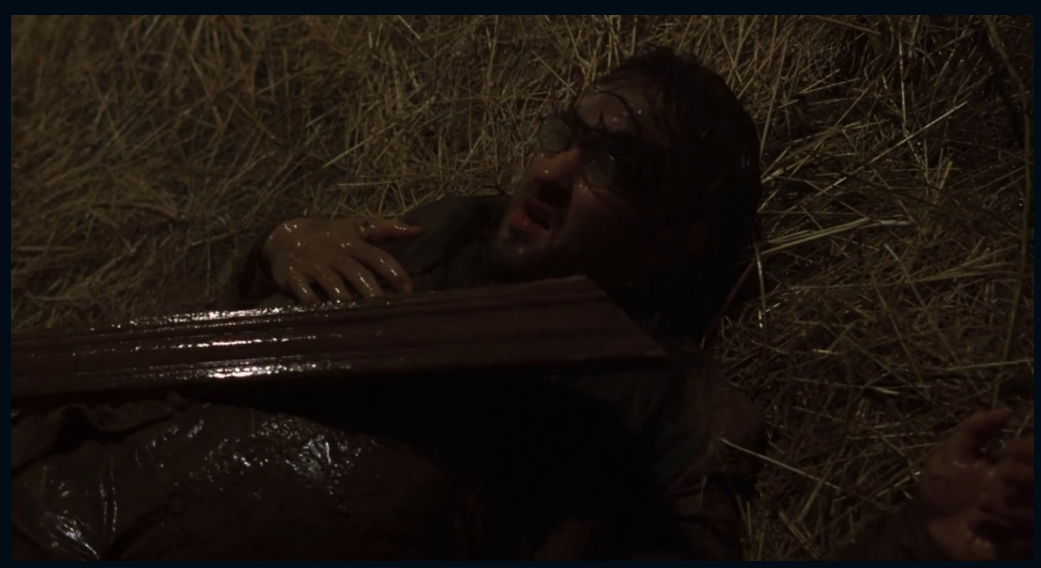

Figura 9. A queda do titereiro. ${ }^{11}$

Pouco depois da saída de Craig, Malkovich encontra-se frente a um espelho, cujos desenhos nele presentes - várias linhas que dividem o reflexo do ator - refletem o caráter multiplicante que recaíra sobre seu corpo. Ademais, temos aqui também o espelhamento das cenas em que o títere vê seu reflexo; a primeira vez que Schwartz vê-se no espelho como Malkovich e a segunda vez, na qual apresenta sua dança e acaba fragmentando o aparato e, antecedendo a desistência, Schwartz-Malkovich fitase no mesmo espelho. Reflexões de reflexões que se reduplicam nessa especularidade. Um labirinto de espelhos refletindo um labirinto identitário; um caleidoscópio de só-reflexão, de dobras e redobras. 


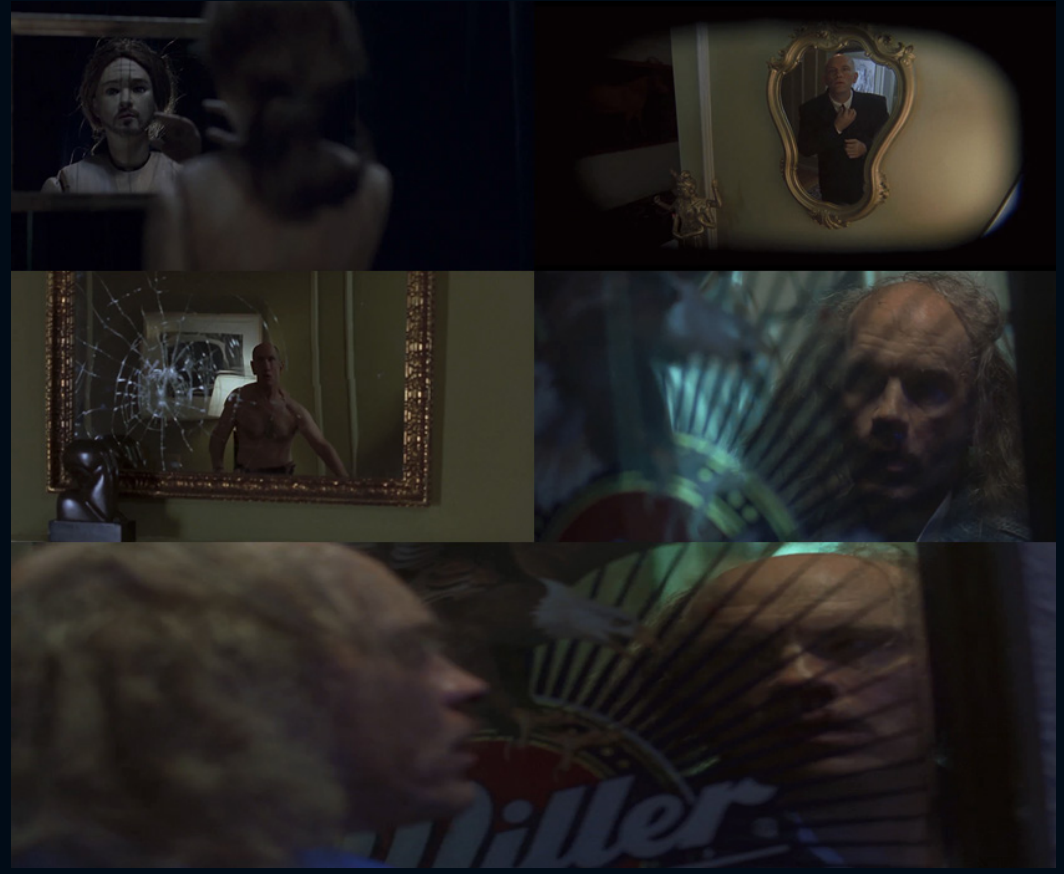

Figura 10. Os espelhos. ${ }^{12}$

Com a casca livre e a meia-noite aproximando-se, Lester e vários de seus amigos entram no portal juntos, incorporando Malkovich nessa compulsória entrada permanente. "Nós somos Malkovich" é uma das primeiras falas do multitudinário homem, evocando a notória passagem do evangelho de Marcos, em que o Cristo encontra e pergunta o nome do endemoniado geraseno, recebendo como resposta: "Legião é o meu nome, porque somos muitos" (BÍBLIA, Marcos, 5:9). O breve momento que John Malkovich readquire o leme de sua corporeidade somente antecede a vinda de muito outros obsessores, a legião que usurpará o seu corpo e identidade.

12 Fonte: Cenas do filme Quero ser John Malkovich. 

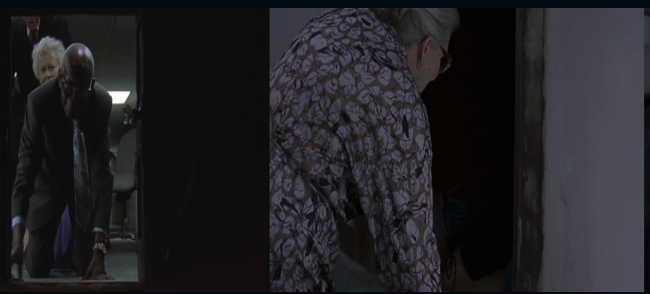

Figura 11. A legião de John Malkovich. ${ }^{13}$

Após toda a experimentação dos clientes da J.M. Inc., do controle de Craig Schwartz, esse corpo mutante agora é alvo de uma drástica exacerbação, distorcendo inclusive o entendimento de corporeidade e mente humanas e passando a tomar uma característica legionária e, por extensão, monstruosa, coadunandose com a visão sobre os monstros de Judith Halberstam:

Os monstros são máquinas significativas. Eles podem representar gênero, raça, nacionalidade, classe e sexualidade num único corpo. E mesmo dentro dessas divisões de identidade, o monstro ainda pode ser decomposto [...] Os monstros e a ficção gótica que os cria são, portanto, tecnologias, tecnologias narrativas que produzem a figura perfeita da identidade negativa. Os monstros têm que ser tudo o que o humano não é [...]. (1995, p.2122 - grifo nosso $)^{14}$

Sete anos transcorrem, então, apresentando-nos um Malkovich em paz que, instado pelas preocupações sobre mortalidade de seu amigo envelhecido Charlie Sheen, resolve revelar-Ihe o seu segredo, apresentando um quarto com fotos de 13 Fonte: Cenas do filme Quero ser John Malkovich.

14 No original: "Monsters are meaning machines. They can represent gender, race, nationality, class, and sexuality in one body. And even within these divisions of identity, the monster can still be broken down. [...] Monsters and the Gothic fiction that creates them are therefore technologies, narrative technologies that produce the perfect figure for negative identity. Monsters have to be everything the human is not [...]". 
uma menina: Emily, a filha de Maxine e Lotte, a próxima casca do túnel lamacento, que, além de viver em alegria com suas mães, porta o isolado e preso Craig Schwartz, assim desvelando a tentativa falha deste de reaver Malkovich ao entrar no túnel após a meia-noite, sendo absorvido pela mente da menina, que está fadada a ser o receptáculo de muitos outros. Retomando Derrida, o phármakon, assim como o túnel, é "[...] sempre uma questão de vida [e] de morte" (2005, p.52).

Aliás, essa "prisão" numa mente outra será um dos motivos no episódio "Black Museum" da quarta temporada da série de web televisão Black Mirror. Tal episódio é composto por três histórias e, numa delas, apresenta-se a possibilidade da transferência de consciência de uma pessoa para outra via um chip que realiza o upload e o download mental, permitindo não só que a consciência implantada tenha acesso à visão do outro, como também possibilitando a comunicação entre as duas mentes. O que se assemelha muito ao filme de Jonze, no quesito de uma mente no interior de outra, embora no episódio não se vê a chance de controle: à mente implantada resta somente a observação do que é visto pelo hospedeiro, resta somente seguir o mesmo destino de Schwartz na cabeça de Emily: a inação.

Com jogos especulares, títeres e titereiros e hordas de identidades num dédalo infindável é que Quero ser John Malkovich pulveriza qualquer ilusão de unidade do eu ou dualidade, ressoando fortemente o que Bauman discursa sobre as incontáveis possibilidades identitárias no século XXI: 
qual das identidades alternativas escolher e, tendo-se escolhido uma, por quanto tempo se apegar a ela? Se no passado a "arte da vida" consistia principalmente em encontrar os meios adequados para atingir determinados fins, agora se trata de testar, um após o outro, todos os (infinitamente numerosos) fins que se possam atingir com a ajuda dos meios que já se possui ou que estão ao alcance. A construção da identidade assumiu a forma de uma experimentação infindável. Os experimentos jamais terminam. Você assume uma identidade num momento, mas muitas outras, ainda não testadas, estão na esquina esperando que você as escolha. Muitas outras identidades não sonhadas ainda estão por ser inventadas e cobiçadas durante a sua vida. Você nunca saberá ao certo se a identidade que agora exibe é a melhor que pode obter e a que provavelmente lhe trará maior satisfação. (2005, p.91-92 - grifo nosso)

É inegável, caso voltemos nosso olhar à nossa realidade, que os processos que são exponenciados, dobrados e redobrados no filme já estão presentes nos dias de hoje, por exemplo, os diversos casos de avatares "falsos" criados em diversas redes sociais ou, um pouco mais recente, o caso do aplicativo FakeApp, capaz de, uma vez alimentado com fotos da pessoa alvo, substituir, num vídeo, o rosto de outro indivíduo pela face do alvo escolhido. $\mathrm{O}$ aplicativo viralizou e uma de suas primeiras "vítimas" foi o ator Nicholas Cage, tendo seu rosto colado sobre outros de variados atores, por exemplo, sobre o de Sean Connery enquanto interpretava o espião James Bond ou sobre a face de um humorista que imitava Cage na sua presença. 


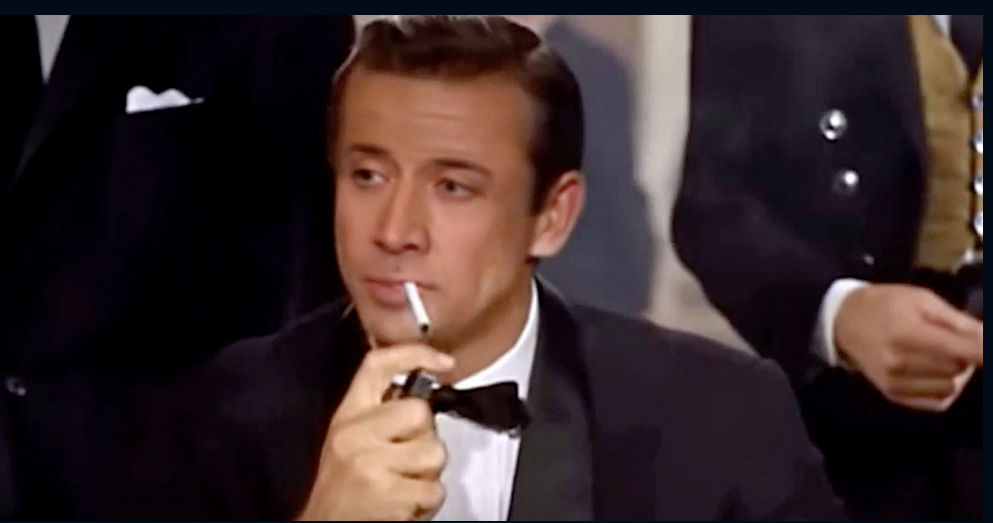

Figura 12. Nicholas Cage como Sean Connery interpretando James Bond. ${ }^{15}$

Coincidentemente, Nicholas Cage participara de um filme roteirizado por Charlie Kaufman e dirigido por Spike Jonze três anos mais tarde, Adaptação. (2002), no qual também há recursos metafílmicos e referências a Quero Ser John Malkovich, além da duplicação do ator, que no filme interpreta Charlie Kaufman e seu irmão gêmeo, Donald Kaufman, ambos tentando elaborar um roteiro de cinema: enquanto o roteiro de Charlie é o mesmo de Adaptação, o de Donald trata-se de um filme detetivesco, cujo policial, criminoso e vítima, ao fim, revelam-se a mesma pessoa, acometida de múltiplas personalidades. Somado ao metarroteiro de Charlie e à duplicidade dos gêmeos Kaufman, observamos a referência a Quero ser John Malkovich no roteiro desenvolvido por Donald, ambos tocando no aspecto de múltiplas identidades. Referências e autorreferências destacam-se, desse modo, como uma das marcas autorais de Spike Jonze e Charlie Kaufman, infletindo, viralmente, esses ecos temática e formalmente em seus filmes. 
Esses indícios intra e extrafílmicos, por conseguinte, apontam a potencialidade dessa replicação de identidade ad absurdum. Quero ser John Malkovich consegue explodir dentro de seu universo, formando corpos monstruosos que incitam "[...] a ruptura de categorias, a destruição de fronteiras e a presença de impurezas [...]" (HALBERSTAM, 1995, p.27) ${ }^{16}$, como também extrapolá-lo, pluralizando os jogos de personalidades com seus atores, roteirista e diretor e, consequentemente, transparecendo a mesma pluralidade que Roland Barthes atribui ao Texto em "Da obra ao texto" (1971):

O intertextual em que é tomado todo texto, pois ele próprio é o entretexto de outro texto, não pode confundir-se com alguma origem do texto: buscar as "fontes", as "influências" de uma obra é satisfazer ao mito da filiação; as citações de que é feito um texto são anônimas, indiscerníveis e, no entanto, já lidas: são citações sem aspas. A obra não perturba nenhuma filosofia monista (existem, como se sabe, antagonistas); para essa filosofia, o plural é o Mal. Assim, diante da obra, o Texto poderia tomar por divisa a palavra do homem possuído pelos demônios (Marcos, 5, 9): "O meu nome é legião, pois nós somos muitos.". (2004, p.71 - grifo do autor)

Lançado próximo do fim do século XX, Quero ser John Malkovich permeia o debate sobre a identidade, promovendo distorções extremas sobre o eu, o outro e as várias personalidades que desenham o fragmentado quadro do indivíduo humano e se juntando a vários outros filmes que abordam esse tema recorrente na ficção, como são exemplos os recentes Fragmentado (2016),

16 No original: "[...] the disruption of categories, the destruction of boundaries, and the presence of impurities [...]". 
cujo protagonista possui vinte e três personalidades e prestes a abarcar uma vigésima quarta, a "Besta", e Star Wars: Episódio VIII Os Últimos Jedi (2017), em que a personagem Rey em seu contato com as trevas da Força, vê-se multiplicada ad infinitum frente a um espelho numa caverna.

A própria ficção sobre identidades, duplos e múltiplas personalidades, caminha nesse ritmo alucinante, duplicando-se e se disseminando numa verve infinda e incansável, remodelando e desdobrando legiões e hordas, sejam elas personas, reflexos, sombras, bonecos ou Malkoviches.

\section{REFERÊNCIAS}

BARTHES, Roland (2012). "Da obra ao texto". In: . O rumor da língua. 3.ed. São Paulo: Martins Fontes. p.65-75.

BAUDRILLARD, Jean (1991). "A precessão dos simulacros". In: Simulacros e simulação. Lisboa: Relógio d’Água. p.7-57.

(2004). A transparência do mal: ensaios sobre os fenômenos extremos. 8.ed. Campinas: Papirus.

BAUMAN, Zygmunt (2005). Identidade: entrevista a Benedetto Vecchi. Rio de Janeiro: Jorge Zahar.

A BÍBLIA de Jerusalém (1981). São Paulo: Paulinas.

DERRIDA, Jacques (2005). A farmácia de Platão. 3.ed. rev. São Paulo: Iluminuras.

. (1981). "The Double Session". In: . Dissemination. London: Athlone Press. p.173-286.

ECO, Umberto (1989). "Sobre os espelhos". In: Sobre os espelhos $e$ outros ensaios. Rio de Janeiro: Nova Fronteira. p.11-37.

FREUD, Sigmund (1996). "O 'estranho'”. In: . Edição standard brasileira das obras psicológicas completas de Sigmund Freud. Rio de Janeiro: Imago, v.XVII. p.233-273. 
HALBERSTAM, Judith (1995). Skin Shows: Gothic Horror and the Technology of Monsters. Durham; London: Duke University Press.

JONZE, Spike (1999). QUERO ser John Malkovich. Universal City, CA: Focus Features LLC. (112 minutos).

PRICE, Rob (2018). People are using creepy, cutting-edge Al technology to splice Nic Cage into every movie they can think of. In http://www.businessinsider. com/nicolas-cage-inserted-movies-fakeapp-ai-technology-2018-1? $r=U S \& \mid R=T$ Acesso em 07.Mai.2018.

RANK, Otto (2013). O duplo: um estudo psicanalítico. Porto Alegre: Dublinense. ROSSET, Clément (2008). O real e seu duplo: ensaio sobre a ilusão. 2.ed. rev. Rio de Janeiro: José Olympio.

SARTRE, Jean-Paul (1977). Entre quatro paredes. São Paulo: Abril Cultural.

SOUZA, Vinicius Lucas de; ROSSI, Aparecido Donizete (2016). “O médico, o monstro e os outros". Abusões, Rio de Janeiro, v.3, 2016, p.188-229. In http://www.epublicacoes.uerj.br/index.php/abusoes/article/view/25950/19284 Acesso em 07.Mai. 2018. 